\title{
AUTONOMÍA ECONÓMICA Y DESCENTRALIZACIÓN FISCAL EN EL ESTADO SOBERANO DE BOLÍVAR, 1857-1886*
}

\author{
Roicer Alberto Flórez Bolívar ${ }^{* \star}$ \\ Sergio Paolo Solano de las Aguas ${ }^{\star \star \star}$
}

\section{Resumen}

En el artículo se analiza el impacto que tuvo la autonomía económica y la descentralización fiscal en el Estado soberano de Bolívar y sus distritos entre 1857 y 1886. La idea central del texto es que al quedar bajo control de la Nación el cobro de las aduanas, el Estado Soberano de Bolívar gravó las actividades económicas más importantes de sus habitantes, lo que tuvo un impacto negativo sobre los distritos al contar con pocas alternativas para crear nuevos impuestos porque las actividades y productos gravables ya lo habían sido por la Nación o por el Estado. Esto último terminó enfrentando a los distritos con el Estado por el control de los escasos recursos económicos de que se disponía. De esta forma, el sistema rentístico establecido por el Estado Soberano de Bolívar en vez de fomentar la descentralización política, administrativa y económica, lo que hizo fue generar una centralización fiscal de los impuestos.

Palabras claves: Estado Soberano de Bolívar, distritos, autonomía económica, descentralización, sistema fiscal.

\footnotetext{
* Artículo de investigación, tipo 3: de revisión, según categoría de Colciencias.

** Magister en historia del convenio Universidad de Cartagena/Universidad Pedagógica y Tecnológica de Colombia, profesor de tiempo completo del Programa de Historia, Facultad de Ciencias Humanas, Universidad de Cartagena de Indias (Colombia) y miembro del grupo de investigaciones Frontera, Sociedad y Cultura de esa unidad docente reconocido por Colciencias en categoría A1.E-mail: rflorezb@unicartagena.edu.co.

* Licenciado en ciencias sociales y económicas de la Universidad del Atlántico, Profesor de tiempo completo del Programa de Historia, Facultad de Ciencias Humanas, Universidad de Cartagena de Indias (Colombia) y miembro del grupo de investigaciones Frontera, Sociedad y Cultura de esa unidad docente reconocido por Colciencias en categoría A1. E-mail: ssolanod@unicartagena.edu.co.
} 


\begin{abstract}
The article analyzes the impact of the economic autonomy and fiscal decentralization in the sovereign state of Bolivar and its districts between 1857 and 1886. The central idea of the text is that to be under control of the nation the collection of customs, the Sovereign State of Bolívar taxed the most important economic activities of its inhabitants, which had a negative impact on the districts since they had few alternatives to create new taxes due to the activities and the production that could be taxed or were burdened by the nation or they were by the sovereign state. The latter ended up causing disputes between the districts and the state for the control of scarce economic resources that were available. Thus, the rent system established by the State, rather than promote political, administrative and economic, which it did was to generate a fiscal centralization of taxes.
\end{abstract}

Key words: sovereign state of Bolivar, districts, economic autonomy, decentralization, fiscal system.

\title{
Presentación
}

El 14 de marzo del año 2010, se realizaron elecciones en Colombia con el fin de escoger a los nuevos miembros del Congreso de la República y a los candidatos presidenciales de algunos partidos y movimientos políticos. Sin embargo, estas elecciones tuvieron para los habitantes de la Costa norte de Colombia un valor adicional consistente en la experiencia pedagógica llamada "Consulta Caribe", que buscaba que los ciudadanos votaran a favor para que los departamentos costeños constituyan la región Caribe como una entidad territorial de derecho público con autonomía política, administrativa y financiera dentro del Estado de Colombia. En últimas, esta experiencia pedagógica, que no era vinculante y no tenía efectos jurídicos, se propone la construcción del modelo de Estado regional en el país para acabar con los desequilibrios del desarrollo territorial y que en el caso particular del Caribe colombiano se evidencian en que, aunque concentra el $21 \%$ de la población del país, tiene el $14.4 \%$ del Producto Interno Bruto y el $47 \%$ de su población en pobreza. Finalmente, la consulta fue respaldada por los ciudadanos en las urnas (El Tiempo, 2010, octubre 10).

Sin embargo, es importante destacar que no es la primera vez que en esta parte de Colombia se exige autonomía política y económica. En los siglos XIX y XX, sectores políticos y económicos visualizaban que el desarrollo de esta región descansaba sobre este proyecto ${ }^{1}$. Un caso significativo de defensa de la autonomía de la Costa en el siglo

\footnotetext{
${ }^{1}$ En el siglo XIX, un acontecimiento que mostró el deseo de las regiones del país de lograr autonomía política fue la denominada "Guerra de los Supremos", guerra que en la Costa tuvo un desarrollo importante. Y para el siglo XX, una experiencia muy reveladora fue "La Liga Costeña de 1919" en la que una parte muy significativa de políticos
} 
XIX fue el de Juan José Nieto, quien en 1835 le escribía al Presidente de la República, Francisco de Paula Santander, manifestándole que el principal problema para el funcionamiento adecuado del régimen provincial en todo el territorio neogranadino residía en la incapacidad de las provincias para disponer de recursos económicos, e intentaba demostrarle: "Las ventajas que en mi escasa comprensión reportaría a la Costa con la variación del sistema contrayéndome solamente a... la provincia de Cartagena, una de las mejores de la República, por su situación geográfica, y sin que su dicha dependa de la voluntad ajena...". (Conde, 2009, p. 273.)

Aunque la defensa de Nieto de la autonomía política y económica fue significativa, esta solo se materializaría en la segunda mitad del siglo XIX con la adopción del sistema de gobierno federalista en Colombia; sistema que logró abrirse camino en la Nueva Granada con la aprobación de la Constitución de 1853, en la que se otorgó cierta autonomía a las provincias, y llegó a su esplendor en 1863, cuando el país se organizó en nueve Estados federales: Antioquia, Bolívar, Boyacá, Cauca, Cundinamarca, Magdalena, panamá, Santander y Tolima. El máximo interés de los constituyentes de 1863 estuvo puesto en fortalecer los poderes locales y regionales y dar autonomía económica, política, administrativa, judicial y eleccionaria a los Estados Soberanos. (Palacio, 1986; Delpar, 1994; Gilmore, 1995; González, 1997; Palacio \& Safford, 2002; Sierra mejía; 2006).

En el caso del Estado soberano de Bolívar, su nombre era un reconocimiento a la memoria del Libertador y su soporte territorial (conformado por los territorios de los actuales departamentos de Bolívar, Sucre, Córdoba y Atlántico) fue la colonial provincia de Cartagena, que se extendía desde el margen occidental del río Magdalena hasta los límites con el actual Chocó, incluyendo el golfo de Urabá, y limitaba al sur con las provincias de Popayán, Antioquia y Vélez. Durante algunos decenios también comprendió al actual departamento insular de San Andrés y Providencia. La extensión del territorio era de 65.303 kilómetros cuadrados y fue organizado para efectos administrativos, judiciales y electorales en diez provincias: Barranquilla, Carmen, Cartagena, Corozal, Chinú, Lorica, Magangué, Mompox, Sabanalarga y Sincelejo (Ver mapa del Estado soberano de Bolívar). A su vez, éstas últimas fueron divididas en distritos. Las capitales de las provincias serían respectivamente los distritos con los nombres de aquellas. (Mendoza Candelo, 1996; Solano, Flórez, Malkún, 2008).

Obedeciendo a la ley de descentralización de rentas y gastos, a cada distrito le correspondía decretar impuestos sobre los productos o efectos que no estaban gravados por la Nación o por el Estado; la administración, recaudación, contabilidad e

\footnotetext{
costeños buscaron crear este movimiento con el fin de exigir mayor atención por parte del gobierno central y defender los intereses de la Costa. Sobre la Guerra de los Supremos y la liga Costeña al respecto ver: Orlando Fals Borda. Historia Doble de la Costa, Tomo $N^{\circ}$ 2, El presidente Nieto, Bogotá, Coed, Banco de la República/Universidad Nacional de Colombia, sede Bogotá, 2002 y Eduardo Posada Carbó. "La Liga Costeña de 1919, una expresión de poder regional”. En: Boletín Cultural y Bibliográfico N 3, Vol. XXII, Bogotá, Banco de la República, 1985, pp.22-28.
} 
inversión de sus propias rentas; la facultad de determinar sus gastos; crear y dotar los empleos necesarios para el servicio del distrito o declarar estos onerosos; la construcción y conservación de escuelas, cárceles, cementerios y demás edificios públicos que fueran necesarios; además todo lo relativo a la policía. Estos asuntos estaban a cargo de un Concejo municipal, única autoridad que podía determinar la manera de administrarlos y disponer cuanto fuera conveniente a los intereses locales sin invadir las atribuciones del Estado, ni las de los demás distritos (Biblioteca Luís Ángel Arango [en adelante BLAA], Gaceta de Bolívar, 1865, agosto 13), .

Ahora bien, es importante señalar que pese a lo importante del tema, el Estado Soberano de Bolívar no cuenta con estudios sistemáticos. Solo se encuentran referencias en algunos libros y artículos como consecuencia obligada de su ubicación temporal como, por ejemplo, en el tomo IV de la "Historia General de Cartagena" de Eduardo Lemaitre. En este tomo, dedicado al periodo republicano, Lemaitre escribió un corto número de páginas sobre el periodo radical y el Estado soberano de Bolívar que se sintetizan en la persona de Juan José Nieto. (Lemaitre, 1983). De igual forma, también encontramos referencias en los trabajos de Orlando Fals Borda, Jorge Restrepo y Manuel Rodríguez, Eduardo Posada Carbó y Greis Verbel. (Fals, 2002; Restrepo \& Rodríguez, 1986; Posada, 1998; Verbel, 2009). El único artículo existente sobre el Estado soberano de Bolívar es el de Alberto Wong Hiu y su objetivo es describir la economía estatal. (Wong Hiu, 1999). 
Figura No. 1

Mapa Estado Soberano de Bolívar

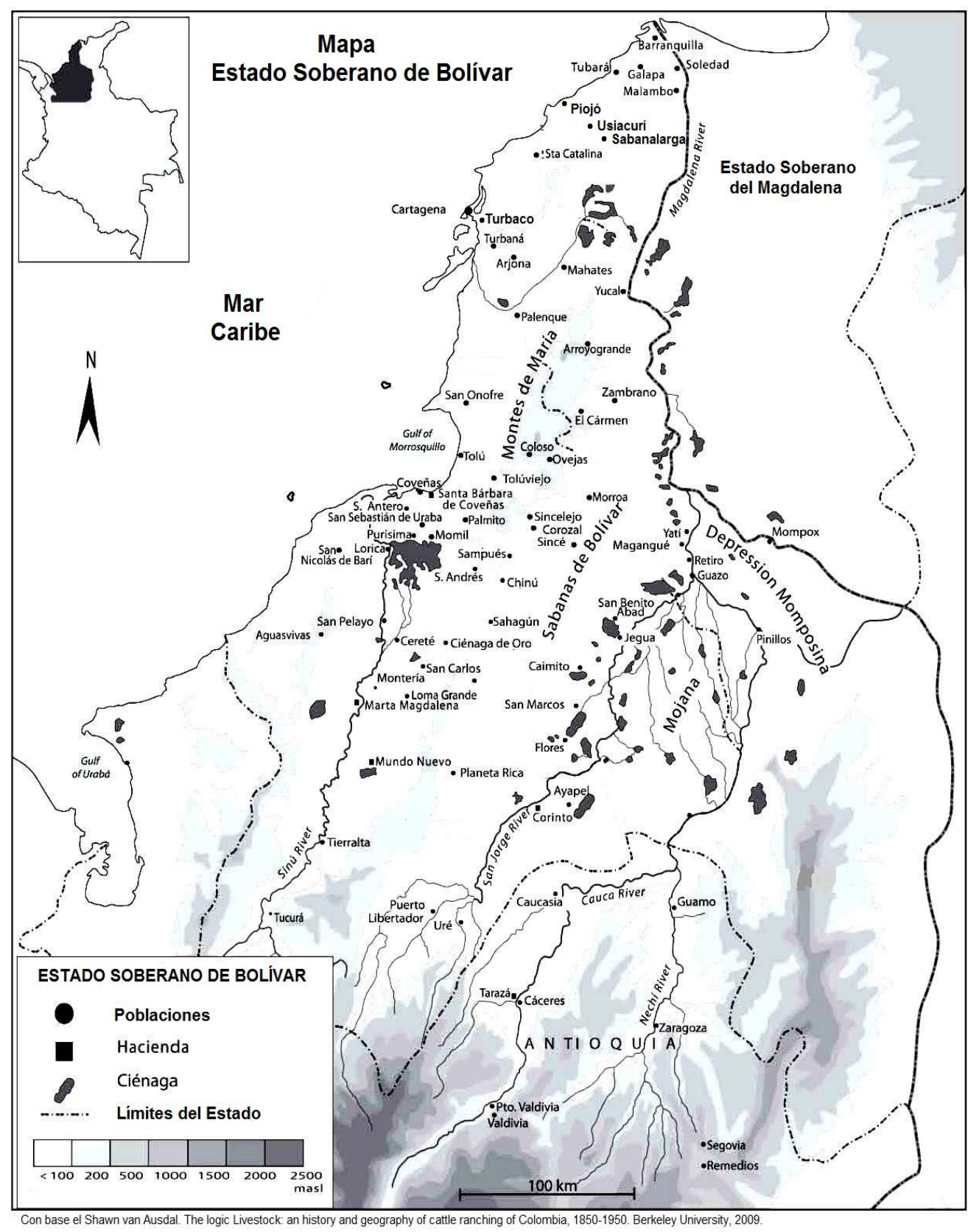

Fuente: Van Ausdal, Shawn. (2009). The logic livestock an history and geography of cattle ranching of Colombia, 1850-1950. Berkeley University. 
Situación distinta es la que se da con los otros Estados, los que cuentan con un número significativo de investigaciones, en las que priman el análisis sobre la educación y las elecciones, como lo demuestran los trabajos de Pedro Ramírez Bustos, Jairo Ramírez Bahamón, Miriam Baez Osorio, Alonso Valencia Llano, Luís Javier Ortiz, María Dotor Robayo, Jorge Enrique Gonzaléz, Luis Javier Villegas y Luis Alarcón, Jorge Conde y Adriana Santos. (Ramírez Bustos, 2002; Ramírez Bahamón, 2004; Baez, 1996, 2004; Valencia, 1998; Ortiz, 1988; Dotor Robayo, 2002; González, 2005; Villegas, 1991; Alarcón, 1999; Alarcón, Conde \& Santos, 2002).

Ante esta realidad, es pertinente preguntarse: ¿Qué justifica el escaso interés de la historiografía regional sobre el Estado soberano de Bolívar? Dos razones explican esta situación. La primera es que se da el caso de que la historiografía regional es muy proclive a la centralidad espacial y política de sus discursos, que hace de los epicentros urbanos más importantes el centro de gravedad de sus reflexiones. El concentrar sus esfuerzos investigativos en algunos espacios locales (Barranquilla y Cartagena) lleva a que la historiografía regional suplante la(s) historia(s) de la región con la de sus principales centros urbanos. Se trata de una reproducción a escala del centralismo historiográfico que hace pasar la historia de sus ciudades portuarias como las historias del resto de la región. En parte, esto se debe a que sin duda esta última es una construcción histórica en la que los centros económicos y de poder más importantes ocupan un lugar central en la integración del espacio y de las formas de vida².

\footnotetext{
${ }^{2}$ Una muestra de lo anterior son los siguientes trabajos: Teodoro Nichols. Tres puertos de Colombia, Bogotá, Banco popular, 1973; Milton Zambrano. El desarrollo del empresariado en Barranquilla. Barranquilla: Uniatlantico, 1998; Sergio Solano. "Acumulación de capital e industrias. Limitaciones en el desarrollo fabril de Barranquilla, 19001934”, en: Historia y Cultura $N^{\circ}$ 2, Cartagena, Universidad de Cartagena; 1994. Adolfo Meisel. “¿Por qué se disipó el dinamismo industrial de Barranquilla?", en: Lecturas de economía $N^{\circ} 23$, Medellín, Universidad de Antioquia, 1987; Joaquín Viloria. Empresas y empresarios de Santa Marta durante el siglo XIX: El caso de la familia De Mier, Bogotá, Universidad de los Andes, 2002; Jorge Restrepo y Manuel Rodríguez. "La actividad comercial y el grupo de comerciantes de Cartagena a fines del siglo XIX”, en: Estudios Sociales $N^{o} 1$, Medellín, Faes, 1986; María Teresa Ripoll. Empresarios centenaristas en Cartagena. Cuatro estudios de caso, Bogotá, Universidad de los Andes, 2007. Steinar A. Saether. Identidades e independencia en Santa Marta y Riohacha, 1750-1850, Bogotá, Ed. Icanh, 2005. María Teresa Ripoll. La élite en Cartagena y su tránsito a la República. Revolución política sin renovación social, Bogotá, Universidad de los Andes, 2008, Jorge Conde. "La República ante la amenaza de los pardos", en: Memorias de X Cátedra anual de historia "Ernesto Restrepo Tirado. El Caribe en la nación colombiana, Bogotá, Coed. Museo Nacional de Colombia/Observatorio del Caribe colombiano, 2006; Marixa Laso. "Un mito republicano de armonía racial: raza y patriotismo en Colombia, 1810-1812", en: Memorias del Simposio: "Cartagena de Indias durante la Independencia", Cartagena, Banco de la República/Observatorio del Caribe colombiano, 2007 y "El día de la Independencia: una revisión necesaria. Acción política afrocolombiana y narrativas patrióticas criollas, Cartagena, 1809-1815, en: Revista de estudios sociales $N^{\circ} 32$, Bogotá, Universidad de los Andes, 2006; Aline Helg. "El General Padilla en su laberinto: Cartagena en el decenio de 1820", en: Haroldo Calvo y Adolfo Meisel, Comp., Cartagena de Indias en el siglo XIX, Cartagena, Universidad Jorge Tadeo Lozano/Banco de la República, 2002; María Aguilera y Adolfo Meisel. "Análisis del censo parcial de Cartagena, 1875", en: Cuadernos de historia económica y empresarial, $N^{\circ}$ 2, Cartagena, Banco de la República, 2006; Eduardo Posada Carbó. "Núñez y Cartagena en la política nacional, 1886-1894", en: Haroldo calvo y Adolfo Meisel (Comp.). Cartagena de Indias en el siglo XIX...; Luís Troncoso. "Crisis y renovación del conservatismo cartagenero, 1895-1909”, en: El Taller de la Historia $N^{\circ}$ 1, Cartagena, Universidad de Cartagena, 2001; Alfonso Fernández. "Clientelismo y Guerra civil en
} 
La segunda razón se debe a que la presencia de altos índices de atraso económico, educativo, de infraestructura en el Caribe colombiano; el desgreño administrativo de los años 1960s a 1980s y un contexto de debates nacionales sobre las relaciones entre las regiones y el centro político-administrativo, obligaron a que en la agenda investigativa de la reciente historiografía costeña ocupara un primer lugar la necesidad de explicar las razones de ese atraso en el marco de los estudios sobre el funcionamiento del modelo agroexportador. En orden de prioridades, uno de los temas que más ha concentrado las cavilaciones de esta historiografía es el de la función que ocupa la infraestructura portuaria y el impacto de su modernización sectorial en el orden de jerarquía de los circuitos mercantiles del modelo agroexportador. De ahí fueron surgiendo las investigaciones sobre la formación de la élite empresarial, abordando interrogantes acerca de sus orígenes, el desarrollo de una mentalidad especulativa, la diversificación de sus inversiones y los contextos económicos y políticos en los que opera. (Rhenals \& Flórez, 2009).

En definitiva, estas razones han determinado que existan áreas, temas y periodos históricos del siglo XIX que no han sido abordados sistemáticamente por los historiadores del Caribe colombiano, sobre todo el que tiene que ver con la existencia del Estado soberano de Bolívar. Verbigracia, existe muy poco conocimiento sobre cuáles eran las principales rentas del Estado y de los distritos y qué factores entorpecían la recolección de las mismas. El estudio del sistema fiscal durante este periodo resulta sugestivo porque la descentralización administrativa supuso que tanto el Estado como los distritos debían generar ingresos económicos para mantener su administración pública. En ese sentido, es necesario preguntarse ¿de qué vivía el Estado, si su principal renta que podía ser la aduana quedó en manos de la Nación? y en el caso de los distritos, al no poder gravar con impuestos a los productos que ya lo habían sido por la Nación y el Estado, ¿qué alternativas tenían, siendo que la principal actividad económica como lo era la ganadería ya había sido gravada por el Estado?

Teniendo en cuenta lo anterior, en este artículo analizamos el impacto que tuvo la autonomía económica y la descentralización fiscal en el Estado soberano de Bolívar y sus distritos entre 1857 y 1886 . La idea central del texto es que al quedar bajo control de la Nación el cobro de las aduanas, el Estado Soberano de Bolívar gravó las actividades económicas más importantes de sus habitantes, lo que tuvo un impacto negativo sobre los distritos al contar con pocas alternativas para crear nuevos impuestos porque las pocas actividades y productos gravables ya lo habían sido o por la Nación o por el Estado. Esto último terminó enfrentando a los distritos con el Estado por el control de los escasos recursos económicos de que se disponía. De esta forma, el sistema rentístico establecido por el Estado Soberano de Bolívar en vez de fomentar

Cartagena. Sobre las estrategias políticas de la élite cartagenera, 1885-1895”, en: Memorias. Revista digital de historia y arqueología desde el Caribe $N^{\circ}$ 2, Barranquilla, Uninorte, 2005; Raúl Román. "Memoria y contramemoria. El uso público de la memoria histórica en Cartagena”, en: Desorden en la plaza. Modernización y memoria urbana, Cartagena, Instituto de patrimonio y cultura de Cartagena, 2002. 
la descentralización política, administrativa y económica, lo que hizo fue generar una centralización fiscal de los impuestos.

\subsection{Algunas características del sistema tributario del Estado Soberano de Bolívar.}

En la década de los sesentas del siglo XIX, cada uno de los Estados Soberanos de los Estados Unidos de Colombia, amparados en la autonomía política y económica de que disfrutaban, organizó su sistema de rentas y las actividades a gravar. La polémica estaba en si se establecía un sistema tributario de características directas que gravara los ingresos o uno indirecto con base en los impuestos al consumo. El problema que veían algunos liberales con ésta última alternativa era que resultaba inequitativa porque no se tenía en cuenta la renta de cada uno de los ciudadanos y debían pagar el mismo gravamen. Para muchos liberales, la equidad sobre la que se basaba el sistema tributario directo lo convertía en el más aceptable y tolerable, porque en él se contemplaba la fórmula de que todo ciudadano, sin distinción alguna, tenía la obligación de contribuir a los gastos inherentes del Estado y dichas contribuciones se repartían entre todos en proporción a sus facultades y no distorsionaba el funcionamiento del mercado. (Bushnell, 1985; Deas, 1993; Palti, 1994; Riguzi, 2000; Jacobsen, 2007; Donjuan, 2008).

En el caso del Estado Soberano de Bolívar, su sistema tributario se caracterizó por ser de naturaleza mixta, al combinar impuestos directos (impuesto sobre la renta) con indirectos (impuesto al consumo de carnes de ganado vacuno y de cerdo, de harina, de azúcar, de tabaco, de café y de cacao, impuesto a la destilación y rectificación de aguardientes y otros). Ahora bien, este sistema tributario descansaba, en su mayor parte, sobre los impuestos indirectos al gravar, principalmente, los productos de consumo.

Los impuestos al consumo de carne de ganado vacuno y de cerdo, sobre la renta y el de destilación y rectificación de aguardientes eran los más importantes para el Estado ya que representaban entre el $80 \%$ y el $85 \%$ de su presupuesto. Por ejemplo, en los años transcurridos entre 1869 y 1878, las sumas adjudicadas a estos impuestos en el presupuesto son las registradas en el cuadro I. 
Cuadro No. 1

Sumas adjudicadas a los principales impuestos del Estado de Bolívar, 18691878

\begin{tabular}{|c|c|c|c|}
\hline Año & $\begin{array}{c}\text { Consumo de } \\
\text { carne } \\
\text { y vacuno y } \\
\text { cerdo }\end{array}$ & $\begin{array}{c}\text { Impuesto sobre la } \\
\text { renta }\end{array}$ & $\begin{array}{c}\text { Destilación, rectificación e } \\
\text { Introducción de } \\
\text { aguardiente }\end{array}$ \\
\hline 1869 & 75.000 & 60.000 & 19.000 \\
\hline 1873 & 85.000 & 27.000 & 17.000 \\
\hline 1874 & 85.000 & 50.000 & 25.000 \\
\hline 1875 & 90.000 & 64.000 & 13.100 \\
\hline 1876 & 90.000 & 80.000 & 12.000 \\
\hline 1877 & 90.000 & 100.000 & 12.000 \\
\hline 1878 & 90.000 & Suprimida & 12.000 \\
\hline
\end{tabular}

Fuente: BLAA, Gaceta de Bolívar, Cartagena, 1870, enero 3; 1873, enero 2; 1873, diciembre 31; 1875, enero 4; Diario de Bolívar, Cartagena, 1875, noviembre 29 ; 1876, noviembre 29; 1877, diciembre 15 .

Pero si tomamos el presupuesto del Estado de 1869, (ver cuadro II) que ascendía a la suma de $\$ 184.800$, sumamos el valor de los impuestos al degüello, sobre la renta y destilación y rectificación de aguardientes, que era de $\$ 154.000$, y aplicamos una regla de tres simples para conocer el porcentaje que representaban, el resultado que se obtiene es el de $83,3 \%$ del total. Individualmente, el impuesto al degüello representaba: $40,5 \%$ del total; el impuesto sobre la renta: $32,4 \%$ y el de destilación y rectificación de aguardientes: $10,2 \%$. El 16,9\% restante se dividía entre impuestos menores como el consumo de harina, azúcar, café y tabaco, equivalente al $5.4 \%$, que representado en peso eran $\$ 10.000$; papel sellado el $4.3 \%$ (\$8.000); registro de instrumentos públicos y privados el $1.3 \%$ equivalente a $\$ 3000$; igual porcentaje que el anterior para las rentas incorporadas. El $4.6 \%$ se dividía entre las mortuorias (\$500); Dique y sus pasos $(\$ 500)$; correos (\$1.300); venta de ediciones oficiales $(\$ 150)$; aprovechamientos $(\$ 100)$; bienes del Estado (\$50) (BLAA, Gaceta de Bolívar, 1870, enero 3). 


\section{Cuadro No. 2}

Presupuesto de rentas del Estado, año 1869.

\begin{tabular}{|c|c|c|}
\hline Cap. & Contribuciones y proventos fiscales & $\begin{array}{l}\text { Monto del } \\
\text { producto } \\
\text { calculado }\end{array}$ \\
\hline 1 & $\begin{array}{l}\text { Destilación, rectificación e introducción de } \\
\text { aguardientes }\end{array}$ & $\$ 19.000$ \\
\hline 2 & Impuesto sobre la renta & 60.000 \\
\hline 3 & Consumo de ganado vacuno y de cerdo & 75.000 \\
\hline 4 & Cría de ganado vacuno & 2.000 \\
\hline 5 & Consumo de harina, azúcar, tabaco, café y cacao & 10.000 \\
\hline 6 & Mortuorias & 500 \\
\hline 7 & $\begin{array}{l}\text { Registro de instrumentos públicos y privados, y } \\
\text { anotación de hipotecas. }\end{array}$ & 3.000 \\
\hline 8 & Dique y sus pasos & 500 \\
\hline 9 & Correos & 1.300 \\
\hline 10 & Venta de edificios oficiales & 150 \\
\hline 11 & Aprovechamientos & 100 \\
\hline 12. & Bienes del Estado & 50 \\
\hline 13 & Papel sellado & 8.000 \\
\hline 14. & Impuesto agrario & 2.000 \\
\hline 15 & Estampillas de correo & 100 \\
\hline 16 & Derecho de minas & 100 \\
\hline 17 & Rentas incorporadas & 3.000 \\
\hline TOTAL & & 184.800 \\
\hline
\end{tabular}


Fuente: BLAA, Gaceta de Bolívar, 1870, enero 12.

\section{Cuadro No. 3}

\section{Principales impuestos del Estado Soberano de Bolívar}

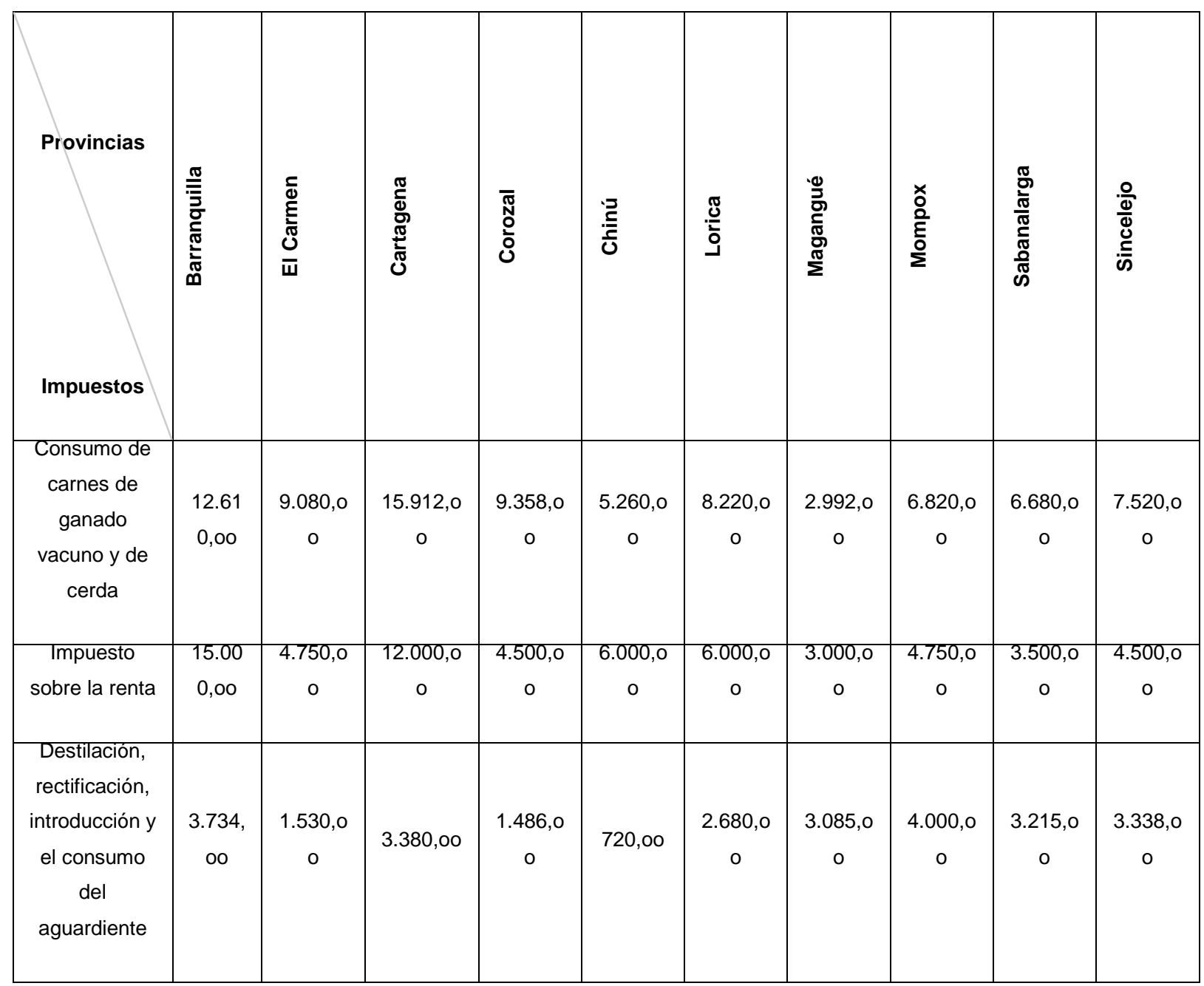

Fuente: BLAA, Gaceta de Bolívar, Cartagena, 1873, octubre 31, noviembre 28, y noviembre 30.

No obstante, los impuestos al degüello, sobre la renta y destilación y rectificación tenían rendimientos diferentes en las provincias como se aprecia en el cuadro III. En las de Barranquilla y Cartagena era "fácil" de cobrar el impuesto sobre la renta. De 
hecho, en 1873 el tesorero general del Estado manifestaba que cada día se hacía más difícil el cobro de este impuesto, pero debía hacer una honrosa mención de la provincia de Barranquilla, "cuyos habitantes contribuyentes de dicho impuesto, lo satisfacen casi en absoluto, religiosamente" (BLAA, Gaceta de Bolívar, 1873, agosto 25). El contraste eran las de Sincelejo y Magangué. En el caso de la primera provincia, en 1874 su gobernador comentaba que la ley sobre el impuesto sobre la renta "ha sido generalmente mal recibida, y si no me equivoco, ella no es solamente mal rechazada sino que hasta su título se ha hecho odioso, y esto es tan cierto, que la mayor parte de los calificados, elude de cualquier manera el pago del impuesto que por ella se establece" (BLAA, Diario de Bolívar, 1874, agosto 14 y 1875, agosto 9). En el caso de Magangué, las razones por las que el rendimiento de este impuesto y el del consumo de carnes de ganado vacuno y de cerdo eran ínfimos, en comparación con Barranquilla y Cartagena, se debía a que era la provincia más pobre y la menos poblada (Flórez, 2009).

Igual sucedía con el impuesto de destilación y rectificación de aguardiente. Las provincias en las que este gravamen producía mayores rendimientos eran Mompox, Barranquilla, Cartagena, Sincelejo, Sabanalarga y Magangué. De estas, la única en la que no se consolidó el cultivo de la caña de azúcar fue la de Barranquilla, pero contaba con el mercado más amplio de todo el Estado. En las que menos producía el gravamen en mención era en las de Chinú, El Carmen y Corozal. La explicación obedecía a que en estas provincias el cultivo de caña de azúcar y la fabricación de aguardientes no eran predominantes, siendo abastecidas por las provincias de Magangué y Sincelejo. (Támara, 1997; Viloria, 2001; Flórez, 2009).

De igual forma, si comparamos lo que produjeron en 1873 los impuestos sobre la renta y el de consumo de carnes de ganado vacuno y de cerdo en las provincias de Barranquilla, la más rica del Estado, y la de Magangué, la más pobre, (ver cuadro IV) podemos sacar algunas conclusiones. La primera es que las rentas producidas por estas dos provincias por concepto de los impuestos arriba señalados eran totalmente diferentes. Mientras que Barranquilla producía por impuesto sobre la renta el $90 \%$ del total de la provincia, Magangué solo llegaba del $40 \%$. En el caso del impuesto al consumo de carnes de ganado vacuno y de cerdo se nota un equilibrio en el porcentaje que representaban ambas capitales: Barranquilla abarcaba alrededor del $63.4 \%$ del total producido en la provincia y Magangué el 55,8\%. 
Cuadro No. 4

Impuestos sobre la renta y el de consumo de carnes provincias de Barranquilla y Magangué

\begin{tabular}{|c|c|c|}
\hline \multicolumn{3}{|c|}{ Provincia de Barranquilla } \\
\hline Distritos & Impuesto sobre la renta & $\begin{array}{l}\text { Consumo de carnes de } \\
\text { ganado vacuno y de cerda }\end{array}$ \\
\hline Barranquilla & $\$ 13.500$ & $\$ 8.000$ \\
\hline Soledad & 460 & 1.610 \\
\hline Sabanagrande & 200 & 600 \\
\hline Santo Tomás & 300 & 1.550 \\
\hline Galapa & $\ldots$. & 400 \\
\hline Tubará & 300 & 550 \\
\hline Malambo & 120 & --- \\
\hline Palmar de Varela & 120 & --- \\
\hline Total & $\$ 15.000$ & $\$ 12.610$ \\
\hline \multicolumn{3}{|c|}{ Provincia de Magangué } \\
\hline Magangué & $\$ 1.200$ & $\$ 1.672$ \\
\hline Majagual & 700 & 385 \\
\hline Sucre & 300 & 660 \\
\hline Yatí & 200 & 100 \\
\hline Madrid & 600 & 75 \\
\hline Palmarito & ....... & 100 \\
\hline Total & $\$ 3.000$ & $\$ 3.992$ \\
\hline
\end{tabular}

Fuente: BLAA, Gaceta de Bolívar, Cartagena, noviembre 28 y 30 de 1873. 
La segunda es que es mucho más notorio el desbalance existente en la provincia de Barranquilla entre su capital y el resto de los distritos, que en la de Magangué. El distrito-capital de Barranquilla aportaba el $90 \%$ del total de la provincia por concepto del impuesto sobre la renta. El restante $10 \%$ se dividía entre los distritos de Soledad, Sabanagrande, Tubará, Malambo, Palmar de Varela. Ahora bien, dentro de estos también había diferencias en lo que producían por el cobro de los impuestos que se están analizando. Soledad aportaba 3\% del impuesto sobre la renta, Tubará y Santo Tomás un $2 \%$, Sabanagrande con el $1.42 \%$ y Malambo y Palmar de Varela con el $0.88 \%$.

Así, lo que se nota en la provincia de Barranquilla es un abismal desbalance en las rentas con las que contaban sus distritos y la concentración de los escasos recursos económicos en la capital provincial. En la de Magangué, aunque había un notable diferencia entre lo que producía su capital y el resto de distritos, esta no era tan inmensa. Por ejemplo, el distrito de Magangué producía el $40 \%$ de lo que se recaudaba en la provincia por el impuesto sobre la renta. Después le seguía Majagual con el $23,3 \%$, Madrid con el $20 \%$, Sucre con el $10 \%$ y Yatí con el $6.6 \%$. En esta provincia no era tan notable la concentración de los escasos recursos en su capital.

En definitivas, en la mayoría de las provincias del Estado existía una profunda crisis económica y administrativa relacionada con la falta de recursos. Por eso, frente al panorama desalentador que presentaban estos entes territoriales, las soluciones que veían algunos gobernadores era suprimirlos, como lo planteo el gobernador de Corozal en 1874. Para este funcionario, aunque la administración pública del Estado perdería, la solución era:

...se suprimieran las entidades provinciales en que está dividido el Estado para su régimen administrativo, y se establecieran jefaturas municipales en cada distrito, que se comunicaran directamente con las oficinas de Ud., y que atendieran a la vez lo político y municipal.

...la suma de $\$ 125.000$ aproximadamente economizaría el Estado con esta medida que someto a la consideración del Poder Ejecutivo;...y no estaría subdividido el Estado en secciones raquíticas como la de Magangué, Sincelejo y esta de mi mando, que sin embargo consumen cantidades considerables en el sostenimiento de sus empleados (BLAA, Gaceta de Bolívar, 1874, julio 30).

Pero, si esta era la situación de las provincias ¿qué sucedía en los distritos?; ¿de qué rentas disponían? el darle respuestas a estos interrogantes es el objetivo de las próximas páginas. 


\section{Autonomía y descentralización fiscal en los distritos.}

Si obedeciendo a la ley de descentralización de rentas y gastos, a cada distrito le correspondía decretar impuestos sobre los productos o efectos que no estaban gravados por la Nación o por el Estado; la administración, recaudación, contabilidad e inversión de sus propias rentas; la pregunta que resulta es: ¿de qué rentas disponían los distritos, siendo que actividades como la ganadería y la fabricación de aguardientes ya había sido gravadas por el Estado?

Al quedarse la Nación con el cobro de las aduanas, el Estado Soberano de Bolívar gravó las actividades económicas más importantes de sus habitantes, lo que tuvo un impacto negativo sobre las economías distritales. Además, por la pobreza de sus habitantes, eran muy pocas las alternativas que tenían las administraciones distritales para establecer nuevos gravámenes, lo que terminó enfrentándolas con el Estado por el control de los escasos recursos económicos de que se disponía. Por ejemplo, en 1867 el gobernador de la provincia de Sabanalarga anotaba lo siguiente:

...el sistema rentístico de los distritos, no necesita ningún esfuerzo para comprender que está sujeto a un verdadero desgreño. Destituidos los distritos de la mayor parte del degüello de ganados que constituía su más pingüe renta, y con la prohibición de establecer impuestos sobre los objetos gravados por el Estado, ha quedado completamente mutilada la soberanía municipal y aquellos sin objetos sobre que imponer contribuciones. (BLAA, Gaceta de Bolívar, 1867, septiembre 10)

Para las autoridades distritales, el sistema rentístico establecido por el Estado en vez de fomentar el federalismo y la descentralización política administrativa, lo que hizo fue generar una centralización fiscal de los impuestos, dejándolos en la completa ruina. De esta manera, la organización federal aparecía como poca innovadora debido a que no provocó una federalización del sistema fiscal, sino solamente un fortalecimiento de la autonomía del Estado, afectando el funcionamiento de la administración pública en los distritos al no contar con suficientes recursos económicos para pagarle a sus empleados; construir escuelas y cárceles y dotar de materiales a las oficinas públicas. (Donjuan, 2008). En 1878 el gobernador de Sabanalarga manifestaba la situación en que se encontraban los distritos de su provincia:

Los distritos de Candelaria, Campo de la Cruz, Juan de Acosta, Manatí, Palmar de Candelaria, Piojó, Repelón, Soplaviento y Usiacurí, llaman verdaderamente la atención por la escasez de sus productos rentísticos,...pues se ve que el de Campo de la Cruz, que es el que arroja mayor cifra, solo gasta en el servicio de su administración, la suma mensual de $\$ 32,04 \frac{1}{2}$; pero es todavía más notable en el distrito de Soplaviento, que opera el gran milagro de sostener su vida política con solo el gasto mensual de $\$ 2,611 / 2$ centavos. De esto resulta, que el mayor número de los distritos carece de rentas; y por consiguiente, su marcha 
administrativa no puede ser rígida... (BLAA, Diario de Bolívar, 1879, agosto

6)

Frente a este panorama desalentador, lo que hicieron las autoridades estatales fue cederle a los distritos algunos de los impuestos que estaban bajo su mando, como la venta al por menor de aguardientes, y darle un tercio de lo recaudado por impuesto al degüello, lo que se conocía como las terceras municipales. Como el dinero que se cancelaba por cada res que se sacrificaba era de $\$ 3,20$ y de esto se descontaba un $8 \%$ por concepto de la recolección, es decir 25, 6 centavos, a las arcas del Estado entraban $\$ 1,96$ y a la de los distritos 97 centavos.

Sin embargo, lo que se recaudaba por la venta al por menor de aguardientes y las terceras municipales no eran suficientes para cubrir los gastos que demandaban la administración pública de los distritos. En el caso del primer impuesto era difícil obtener grandes rendimientos porque quienes ejercían esta actividad eran, en su gran mayoría, los ciudadanos más pobres. En 1869, el gobernador de la provincia de Barranquilla manifestaba que: "la venta por menor de aguardiente es el impuesto que más dificultades presenta para su cobro, por la razón de que los individuos que la pagan son en su mayoría enteramente infelices..." (BLAA, Gaceta de Bolívar, 1869, septiembre 12). Dos años después, el gobernador del Carmen también se quejaba por lo que producía este impuesto en su provincia:

Por más esfuerzos que he hecho para regularizar el cobro de este impuesto, nada he logrado. Su producto no está en correspondencia con el número de establecimientos cuyos dueños se ocupan en esta industria. Es escandaloso lo que produce este impuesto en los distritos del Carmen y San Jacinto: en el primero solo aparecen pagándolo por doce puestos y en el segundo hay mes que solo dos son las personas que lo pagan y por igual número de puestos. La única medida que podría normalizar un poco la recaudación de este impuesto sería el remate de él, pero ni con esto he conseguido por falta de licitadores en las veces que he sido autorizado para ello por el poder Ejecutivo. (BLAA, Gaceta de Bolívar, 1871, agosto 24)

Ni siquiera en la provincia de Sincelejo, que era una de las que más producía por concepto de este impuesto, se obtenían buenos resultados. En 1872, su gobernador manifestaba que el rendimiento que se había obtenido por la venta al por menor de aguardiente en Tolú viejo en el semestre corrido desde enero hasta junio de ese año era de $\$ 12$ pesos; es decir, dos pesos por mes (BLAA, Diario de Bolívar, 1872, julio 22).

En cuanto a las terceras municipales, existían razones que determinaban que los ingresos recibidos por los distritos fueran también diferentes. La primera de ellas era por el número de habitantes de cada distrito. No era igual el rendimiento que se obtenía en Barranquilla, Sincelejo y Cartagena, con poblaciones de 11.595, 11.336 y 8.603 
habitantes, respectivamente, al que se tenía en los distritos San Fernando, Arroyo Grande, María la Baja, etc., cuyas poblaciones no llegaban, según el censo de 1881, a los mil habitantes (BLAA, Diario de Bolívar, 1881, diciembre 1). De esta forma, en las tres primeras poblaciones el consumo de carne de ganado vacuno era superior al de las tres últimas. Un ejemplo de lo afirmado fue presentado por el gobernador de Mompox en 1871. Para este funcionario los colectores de los distritos recaudaban muy poco por los impuestos y hasta el consumo de carnes, que era casi la única contribución que percibían, era ridículo. En el caso de Talaigua sus 992 habitantes consumieron 3 cerdos en enero; en Pinillos, los 1.967 habitantes sacrificaron en enero y febrero 2 cerdos; Morales, población de 3.354 habitantes, consumió una res y 3 cerdos en febrero, los 1.884 habitantes del distrito de Simití 3 cerdos en enero; loba, con 1318 habitantes, consumió en marzo 1 res y 6 cerdos; Barranco, que tenía 1.318 habitantes, consumió en febrero 3 cerdos (BLAA, Diario de Bolívar, 1871, agosto 16). De igual forma, el resultado que se obtuvo en las provincias de Corozal, El Carmen y Mompox en marzo de 1873 sobre el consumo de carne en sus distritos es el que aparece en el cuadro V.

Cuadro No. 5

Impuestos recaudados por concepto de consumo de carnes.

\begin{tabular}{|l|c|c|c|c|c|c|c|c|}
\hline \multicolumn{2}{|c|}{ Provincia de Corozal } & \multicolumn{3}{c|}{ Provincia de El Carmen } & \multicolumn{2}{c|}{ Provincia de Mompox } \\
\hline $\begin{array}{c}\text { Distrito } \\
\text { s }\end{array}$ & $\begin{array}{c}\text { Rese } \\
\text { s }\end{array}$ & $\begin{array}{c}\text { Cerdo } \\
\text { s }\end{array}$ & $\begin{array}{c}\text { Distrito } \\
\text { s }\end{array}$ & $\begin{array}{c}\text { Rese } \\
\text { s }\end{array}$ & $\begin{array}{c}\text { Cerdo } \\
\text { s }\end{array}$ & $\begin{array}{c}\text { Distrito } \\
\text { s }\end{array}$ & $\begin{array}{c}\text { Rese } \\
\text { s }\end{array}$ & $\begin{array}{c}\text { Cerdo } \\
\text { s }\end{array}$ \\
\hline Corozal & 96 & 33 & Carmen & 160 & 23 & $\begin{array}{c}\text { Mompo } \\
\text { x }\end{array}$ & 144 & 56 \\
\hline Sincé & 84 & 26 & $\begin{array}{c}\text { San } \\
\text { Jacinto }\end{array}$ & 48 & 12 & $\begin{array}{c}\text { San } \\
\text { Fernan } \\
\text { do }\end{array}$ & 1 & 1 \\
\hline Ovejas & 38 & 5 & $\begin{array}{c}\text { San } \\
\text { Juan }\end{array}$ & 23 & 4 & Loba & 0 & 1 \\
\hline Galeras & 11 & 4 & $\begin{array}{c}\text { Zambra } \\
\text { no }\end{array}$ & 18 & 2 & Pinillos & 3 & 7 \\
\hline Morroa & 1 & 1 & Tetón & 6 & 4 & Simití & 2 & 4 \\
\hline & & & Guamo & 0 & 0 & Morales & 7 & 7 \\
\hline
\end{tabular}




\begin{tabular}{|l|l|l|c|c|c|c|c|c|}
\hline & & Yucal & 0 & 0 & $\begin{array}{c}\text { Talaigu } \\
\text { a }\end{array}$ & 0 & 0 \\
\hline & & $\begin{array}{c}\text { Barranc } \\
\text { a }\end{array}$ & 0 & 0 & $\begin{array}{c}\text { San } \\
\text { Martín } \\
\text { de Loba }\end{array}$ & 0 & 0 \\
\hline
\end{tabular}

Fuente: Archivo Histórico de Cartagena (en adelante AHC), fondo Manuscritos, Sección provincias, caja № 29, 1873, marzo 12.

Otro factor que no favorecía el rendimiento de las terceras municipales se debía a que muchos distritos estaban ubicados a orilla de los ríos, ciénagas, caños, etc. ${ }^{3}$, lugares en los que el consumo de carne no era el alimento principal de la dieta alimenticia, como si lo era el pescado. Los meses más duros para las entradas del impuesto sobre el consumo de carne de ganado vacuno y de cerdo eran de enero a abril, por la competencia que a la carne hacía en ese periodo el pescado. Verbigracia, Luis Striffler, refiriéndose al distrito de San Antonio, dejó consignado que este pueblo:

Es un puerto de bastante animación por motivo del tránsito, pues el lugar por sí mismo no produce nada, a no ser pescado: todos los habitantes son pescadores... Es verdad que no faltan piraguas que suben y bajan y canoas de pescadores, porque la única industria de los habitantes de la boca de San Antonio es la pesquería; delante de todas las casas hay tasajeras guarnecidas de bocachicos, bagres y sábalos los que se secan al sol. (Striffler, 1958, p.25)

Por su parte, en 1865 el gobernador de Mompox le explicaba al secretario general que en esa provincia: "los derechos de matanza son insignificantes porque únicamente en esta ciudad hay consumo de carne. En los otros distritos situados en las márgenes de las varias vías fluviales que riegan ésta sección, la base de la subsistencia... es el pescado; la pobreza por una parte y la abundancia de pescado por otra incita a sus habitantes a adoptar la pesca: bien por oficio, bien por satisfacer las necesidades de sus familias" (BLAA, Gaceta de Bolívar, 1865, julio 23). Nueve años más tarde, en 1874, el prefecto de Mompox le comunicaba al gobernador de la provincia que en los once días que duró en el distrito de Simití: "allí no se mató una res, ni un cerdo: el pueblo se mantenía con insípidos peces de la ciénaga..." (BLAA, Gaceta de Bolívar, 1874, noviembre 10).

Además, en esa misma provincia el impuesto al degüello también se veía afectado por otras causas. La primera, según su gobernador, se debía a que el consumo era

\footnotetext{
${ }^{3}$ Una quinta parte de la superficie geográfica de la Costa Caribe estaba conformada por ríos, caños, Ciénagas y pantanos.
} 
netamente local. En anteriores años, cuando era activa la navegación por botes y champanes, se expendían en esa ciudad grandes cantidades de carnes "para aviar todas esas embarcaciones que subían el Magdalena a pecho de hombre", pero como esa clase de navegación estaba en razón inversa al número de buques de vapor que cruzaban el río, "hoy que once buques de esa clase surcan sus aguas, los botes y champanes han quedado reducidos a los viajes de corta distancia; y muchos de los hombres ocupados en los transportes, han emigrado al Alto Magdalena para ocuparse de la navegación de Conejo a Honda" (BLAA, Gaceta de Bolívar, 1874, noviembre 10).

La otra causa era el contrabando proveniente del Estado del Magdalena ya que lo que se hacía era que se daba muerte a las reses en ese Estado y se introducían las carnes en altas horas de la noche, para luego ser expendidas de una manera sigilosa. Por grande que fuera la vigilancia que se ejerciera por los empleados de policía y de hacienda, en laderas tan extensas, era imposible evitar el fraude como lo ponía de presente en 1870 el gobernador de la provincia:

De todos los impuestos el que más se ha estado defraudando ha sido el de degüello de ganado vacuno y de cerdo... Como esta provincia se encuentra dividida por el rio Magdalena del Estado del mismo nombre, y en muchos lugares de su territorio es fácil mantener salazones e introducir las carnes clandestinamente a este Estado, sin temor siquiera al recargo en el impuesto ni a la multa que para otros casos tiene señalado el distrito, Conveniente sería igualmente poner una cortapisa al efugio a que ocurren los defraudadores de decir y aun comprobar cuando se les aprende el artículo, que lo han importado del Estado vecino y lo destinan para el Banco, lugar perteneciente al mismo Estado. (BLAA, Gaceta de Bolívar, 1874, noviembre 10)

De esta forma, los ingresos recibidos por los distritos por concepto de las terceras municipales eran diferentes. Verbigracia, en 1870 al distrito de Barranquilla le correspondió la suma $\$ 426,90$; El Carmen $\$ 158,02,1 / 2$; Corozal $\$ 102,85$. En contraste, Momíl, Achí, Madrid recibieron las sumas de $\$ 2,83 ; \$ 2,73$ y $\$ 1,45$. Se daban casos extremos como el de Yatí, provincia de Magangué, en el que el impuesto al consumo de carne de ganado vacuno y de cerdo fue arrendado a Pedro Porto por la suma de $\$ 37,50$; por tanto su administración distrital recibió ese año por concepto de la tercera municipal 97 centavos y con esa suma tenía la obligación de pagarle a todos sus funcionarios públicos; construir y mantener la escuela y la cárcel; dotar de los materiales que necesitaban las diferentes dependencias; mejoramiento de las vías y otros (BLAA, Diario de Bolívar, 1870, septiembre 17).

El problema de esta situación era que casi todos los distritos estaban atenidos al recurso precario de la tercera parte del impuesto al consumo de carnes. Cuando por cualquier circunstancia se les retiraban, quedaban sus empleados sin esperanza de que se les remunerara sus servicios, ocasionando irregularidades en la administración pública. Debido a esto, los distritos siempre se encontraban con déficit enormes para 
cancelar las deudas que los apremiaban como lo señalaba en 1877 el gobernador de la provincia de El Carmen:

\begin{abstract}
El tesoro de los distritos está en un estado de postración lamentable. No hay rentas para atender medianamente al pago de los sueldos de los empleados distritoriales. La tercera municipal, el impuesto sobra la venta por menor de aguardientes..., no producen lo suficiente para el objeto indicado. Distritos hay en esta provincia, como Barranca, en que los empleados públicos fundan toda su esperanza en la tercera municipal, que hoy, que dichos derechos están allí rematados, asciende a \$1, 87,1/2. (BLAA, Diario de Bolívar, 1877, julio 28)
\end{abstract}

Entonces, si las terceras municipales y la venta por menor de aguardientes no producían los suficientes recursos para el mantenimiento de la administración pública de los distritos: ¿Qué alternativas planteaban los concejos municipales?, ¿sobre qué otros objetos 0 actividades establecían gravámenes?

\title{
El laboratorio fiscal de los distritos.
}

Efectivamente, casi todos los concejos municipales planteaban alternativas de posibles impuestos que se podían establecer para mejorar las rentas distritales. El problema estaba en que casi no había objetos para gravar legalmente, porque o ya estaban gravados por la Nación o lo estaban por el Estado. Así, a lo que asistimos en el Estado soberano de Bolívar entre 1857 y 1886 es a un verdadero "laboratorio" fiscal en los distritos. Impuestos al pescado salado, ahumado, fresco o frito; a los establecimientos de trapiches para moler caña de azúcar; a los juegos permitidos por la ley en las temporadas de fiestas públicas como roletas, naipes, riñas de gallos; a los bailes; por la pesca del Sábalo, como lo decretó el distrito de Bocachica, provincia de Cartagena, en 1878; a la leña que cortaran para los buques de vapor los que no eran vecinos del distrito de Pinillos; por el uso del peso de los distritos. Se llegó al extremo de incluir en los presupuestos de rentas las multas que se impusieran a las autoridades distritales y el de cancelar 20 centavos los presos por el uso de la cárcel distrital, como lo establecieron los concejos distritales de Morroa y Barranquilla en 1878 (BLAA, Diario de Bolívar, 1876, agosto 14; Gaceta de Bolívar, 1870, agosto 7 y 1868, agosto 27). Lo paradójico del asunto es que en Barranquilla la cárcel era un árbol de mamón como lo ratificó su gobernador: "ni la provincia, ni distrito alguno en ella, tiene edificio que pueda llevar el nombre de cárcel. En algunos de ellos, el tal edificio es un árbol de mamón y el encarcelado tiene que pagar el derecho de carcelaje al carcelero tanto por hora" (BLAA, Diario de Bolívar, 1878, agosto 19). 
Estos eran algunos de los impuestos decretados por los Concejos municipales para mejorar la situación de las rentas distritales, cumplir con las normas constitucionales y llevar a la práctica la premisa liberal que señalaba que los distritos eran la razón de ser del sistema federal. En esa búsqueda de encontrar alternativas el Concejo municipal de Arjona decretó en 1867 el siguiente presupuesto de rentas:

\section{DECRETO SOBRE IMPUESTO:}

El Concejo municipal del distrito....DECRETA:

Art.1. Desde el 1 de Febrero de 1867 quedan gravados en el distrito los ramos y operaciones siguientes:

1. Venta en píe de los ganados vacunos y de cerda.

2. Venta por menor de aguardientes.

3. Venta por menor de pescado salado, ahumado, fresco o frito.

4. Establecimientos de trapiches para moler caña de azúcar.

5. Los juegos permitidos por la ley en las temporadas de fiestas públicas.

Art. 2. El impuesto con que se gravan los ramos y operaciones mencionadas, es el que pasa a expresarse:

1. Por cada res que se venda en pie treinta centavos.

2. Por cada Cerdo, sea macho o hembra, que se venda también en píe, diez centavos.

3. Por cada venta menor de aguardientes un peso al mes.

4. Por cada carga de pescado salado o frito que se venda un peso.

5. Por cada carga de fresco o ahumado, cincuenta centavos.

6. Por cada trapiche establecido para moler caña, cincuenta centavos.

7. Por cada juego de roleta, un peso por cada noche que funcione.

(A.H.C., Manuscritos, Fondo Gobernación, Sección Distritos y Municipios, 1867, enero 31, Caja № 22, Arjona)

Pese a todos estos esfuerzos, la realidad era que ninguno de estos impuestos representaban entradas significativas para las arcas distritales y mucho menos se les podía aumentar su gravamen por la pobreza de los habitantes que vivían de la agricultura y la pesca. Inclusive, algunos distritos pedían ser eliminados y se les concediera la condición de agregación o caserío como lo plantearon en 1870 los vecinos del Pie de la Popa, provincia de Cartagena. Según su gobernador:

Entre los diez y nueve distritos que forman la provincia, con excepción de esta capital, donde por muchas circunstancias las cosas marchan sino bien al menos regular, no hay uno solo que reúna todos los edificios que manda la ley como son casa municipal, casa de escuela, cárcel y matadero y que 
cuente con cementerios y vías públicas debidamente arregladas en todas las estaciones del año, siendo tal la dejación y el poco interés en conservar la entidad distritorial, que no faltan algunos individuos que como los del Pié de la Popa desean que su distrito sea caserío o agregación (BLAA, Gaceta de Bolívar, 1870, octubre 23).

Esta falta de recursos económicos ocasionaba que a los empleados públicos se les retrasara el pago de los sueldos por seis u ocho meses, lo que era la norma, o que tuvieran que venderlos. En 1876, el presidente del tribunal superior de justicia del Estado informaba al secretario general que los empleados que laboraban bajo su dependencia: "se ven forzados a vender sus sueldos con un cincuenta por ciento de descuento" (BLAA, Diario de Bolívar, 1876, julio 15). De igual forma, en el mes de febrero de ese mismo año, el director de la escuela pública de varones del distrito de Rosavieja, provincia de Sabanalarga, vendió los sueldos que recibiría en los meses de enero a junio a Pedro A. Polo y Víctor Manuel Consuegra:

Conste por el presente que cedo y traspaso a favor de los señores Víctor Manuel Consuegra y Pedro A. Polo los sueldos que me corresponden como director de la escuela pública de varones del distrito de Rosavieja correspondientes a los meses de enero y el presente, como también los que devengare en los meses de marzo a junio... de este traspaso he recibido de dichos señores el valor íntegro de los sueldos mencionados. Con su consecuencia me obligó a responder a los referidos Señores Polo y Consuegra del reintegro de dichos sueldos en el caso de que dichos señores no puedan percibirlos por trastorno del orden público o por cualquier caso fortuito yo no pueda devengar los sueldos que les he vendido. (AHC, Manuscritos, Fondo Gobernación, Sección Tesorería. Sabanalarga, 1876, febrero 27)

Además de vender los sueldos, también se daban situaciones extremas como la presentada por el gobernador de la provincia de Chinú en 1880. Según este funcionario: "acaba de suceder a esta gobernación, que habiéndose visto precisada a multar al Sr. Alcalde del distrito de Caimito, este empleado, en la nota que dio las explicaciones del caso por la falta cometida, pidió su remoción como único medio de salvarse de la pesada carga que sobre él habían colocado" (BLAA, Diario de Bolívar, 1880, julio 10).

\section{Reflexiones finales:}

La falta de recursos económicos padecida por los distritos terminó siendo asociada, por un lado, con el sistema tributario montado por el Estado y, por el otro, a la imagen de "centralismo" político practicado por Cartagena, como lo señalaba en 1869 el gobernador de la provincia de El Carmen. Según este funcionario: "se nota un desagrado casi general en la provincia no por los actuales impuestos que forman la renta del Estado, sino por la miseria en que por ellas se encuentran los distritos..." (BLAA, Gaceta de Bolívar, 1869, septiembre 5). Esta situación ocasionaba 
enfrentamientos entre las provincias, los distritos, los gobernadores y alcaldes con el Estado, llevando, incluso, que algunas de las medidas adoptadas por las autoridades estatales fueran saboteadas por las administraciones distritales. Por ejemplo, en la década de los setentas se creo la Junta Central de Agricultura, cuyo objetivo era fomentar el desarrollo de esta actividad económica. (De la Rosa, 2000). Para ello, una de las primeras medidas establecidas por la Junta fue organizar juntas de caminos en todos los distritos con el fin de mejorar las vías de comunicación. Sin embargo, este proyecto atravesó por una serie de vicisitudes, sobresaliendo la resistencia de los habitantes al pago del impuesto ya que veían en esto una muestra más del centralismo político de Cartagena y perseguía recaudar recursos para el desarrollo de sus vías de comunicación, principalmente El Canal del Dique, como lo señalaba el presidente de la junta de caminos de Lorica:

En esta provincia, más que en ninguna otra, se ha hecho odioso este impuesto aun sin haberlo cobrado, por la circunstancia de tener que remitir los distritos parte de lo que recauden a esta capital [Cartagena]; pues maliciosamente han hecho comprender que los fondos que vengan a la capital, se les ha de dar inversión distinta a la que puede satisfacer las necesidades de los distritos contribuyentes. En esta misma capital, la recaudación que hasta ahora se ha hecho es tan exigua que los productos del ramo son sumamente ínfimos. (BLAA, Diario de Bolívar, 1875, julio 13).

Años después, el gobernador de la provincia de Chinú se refería en los mismos términos hacia las medidas implementadas por el gobierno en materia de vías de comunicación. Para el gobernador, las provincias de las Sabanas (Chinú, Sincelejo y Corozal) habían sido víctimas de intereses egoístas y añadía categóricamente: "creo sinceramente que a la capital del Estado no la redime de su agonizante situación la expedita navegación del Dique. Estimo que eso no es más que un paliativo a los males que la agobian, paliativo aplicado a veces por patriotismo, a veces por el empirismo económico. La verdadera tabla de la ciudad Redentora, está en el camino de Tolú a Sahagún, o al menos hasta Sincelejo..." (BLAA, Diario de Bolívar, 1880, agosto 27).

De igual forma, esta disputa entre autoridades estatales y distritales por el control de los escasos recursos económicos quizás ayude a explicar, en parte, la tolerancia mostrada por muchos funcionarios distritales hacia prácticas como el contrabando, la corrupción y la fabricación ilícita de aguardientes. (Fernández, 2005; Laurent, 2008, 2009). De hecho, los impuestos más representativos del sistema tributario del Estado como eran el degüello, el impuesto sobre la renta, la destilación y rectificación de aguardientes, consumo de harina, tabaco, café y azúcar extranjeros eran los que mayormente estaban sujetos a estos actos ilícitos. (Flórez, 2009). Finalmente, la lógica manejada por algunos funcionarios distritales era que estos recaudos no entrarían a las arcas distritales sino a las del Estado. Por eso, el gobernador de la provincia de Mompox en el informe enviado a la asamblea legislativa en 1865 les recordaba a sus miembros que: "sabido es que desde tiempo bien remotos, el contrabando es una profesión; y aunque la ley persiga a los contrabandistas, la sociedad no los detesta, sin 
duda por el antagonismo que siempre ha existido entre el fisco y los contribuyentes" (BLAA, Gaceta de Bolívar, 1865, julio 23).

\section{REFERENCIAS BIBLIOGRÁFICAS}

\section{Fuentes primarias}

Biblioteca Luis Ángel Arango (BLAA), sección de microfilm

- Gaceta del Estado Soberano de Bolívar: Años: 1858, 1859, 1860,1861, 1862, 1863, 1864, 1865.

- Gaceta de Bolívar: Años: 1866, 1867, 1868, 1869, 1870, 1871, 1872, 1873, $1874,1875$.

- Diario de Bolívar: Años: 1875, 1876, 1877, 1878.

Archivo Histórico de Cartagena (AHC)

- Fondo Gobernación: Secciones: Distritos y Municipios; Provincias; Hacienda; Tesorería.

\section{Libros y artículos}

Aguilera, María \& Meisel, Adolfo. (2006). "Análisis del censo parcial de Cartagena, 1875". En: Cuadernos de historia económica y empresarial, $N^{\circ}$ 2. Cartagena: Banco de la República.

Alarcón, Luís. (1999). "Comportamiento electoral y actores políticos en el Estado Soberano del Magdalena". En: Revista Huella $N^{\circ}$ 55.Barranquilla: Universidad del Norte.

Alarcón, Luís, Conde, Jorge \& Santos, Adriana. (2002). Educación y Cultura en el Estado Soberano del Magdalena, 1857-1886. Barranquilla: Universidad del Atlántico, 250 págs.

Báez Osorio, Miriam. (1996). La educación radical en Boyacá. Fundamento social y político. Academia boyacense de historia. Tunja, 110 págs.

(2004). Las escuelas normales y el cambio educativo en los Estados Unidos de Colombia en el periodo radical, 1870-1886. Universidad Pedagógica y Tecnológica de Colombia, Tunja, 447 págs.

Bell Lemus, Gustavo. (1988). "Conflictos regionales y centralismo: una hipótesis sobre las relaciones políticas de la Costa Caribe con el gobierno central en los primeros 
años de la República, 1821- 1840". En: Gustavo Bell Lemus, el Caribe colombiano: selección de textos históricos. Barranquilla: Ediciones Uninorte.

Bushnell, David. (1985). El Régimen de Santander en la Gran Colombia. Bogotá: El Áncora Editores.

Conde, Jorge \& Solano, Sergio. (1993), Elite empresarial y desarrollo industrial en Barranquilla, 1875-1950. Barranquilla: Universidad del Atlántico.

Conde, Jorge. (2006). "La República ante la amenaza de los pardos". En: Memorias de $X$ Cátedra anual de historia "Ernesto Restrepo Tirado. El Caribe en la nación colombiana, Bogotá: Coed. Museo Nacional de Colombia/Observatorio del Caribe colombiano.

Caribe colombiano, 1821-1855. Medellín: La Carreta.

Deas, Malcolm. (1993). "Los problemas fiscales en Colombia durante el siglo XIX”, En: Del poder y la gramática y otros ensayos sobre historia, política y literaturas colombianas, Bogotá: Tercer Mundo Editores, pp. 175-198.

De la Rosa, Yesabeth. (2000). La obra de Francisco Javier Balmaceda en la Junta Central de Agricultura: un pensamiento moderno en el Estado de Bolívar, 18781898. Trabajo de grado para optar al título de historiadora. Facultad de Ciencias Humanas de la Universidad de Cartagena.

Delpar, Helen. (1994). Rojos contra azules. El partido Liberal en la política colombiana, 1863-1899. Bogotá: Coed. Tercer Mundo Editores/ Procultura.

Donjuán Espinosa, Esperanza. "Las finanzas públicas en Sonora en la primera mitad del siglo XIX. La cuestión fiscal”. En: www.cholonautas.edu.pe.bibliotecavirtualdecienciassociales. (Consulta: abril 23 de 2010).

Dotor Robayo, María. (2002). La instrucción pública en el Estado Soberano de Boyacá, 1870-1876. Bogotá: Ministerio de Cultura.

Fals Borda, Orlando. (2002). Historia Doble de la Costa, Tomo $N^{\circ}$ 2, El presidente Nieto. Bogotá: Coed, Banco de la República/Universidad Nacional de Colombia, sede Bogotá.

Fernández, Alfonso. (2005). "Clientelismo y Guerra civil en Cartagena. Sobre las estrategias políticas de la élite cartagenera, 1885-1895”. En: Memorias N². Revista digital de historia y arqueología desde el Caribe. Barranquilla: Uninorte. 
Flórez, Roicer. (2007). El uso privado de la autoridad pública en el Estado Soberano de Bolívar, 1863-1878, Trabajo de grado para optar al título de Magister en Historia, convenio Universidad Pedagógica y Tecnológica de Colombia/Universidad de Cartagena. ingresos fiscales en el Estado Soberano de Bolívar, 1860-1878". En: El Taller de la Historia Vol. 1, No 1. Cartagena: Universidad de Cartagena, pp. 13-40.

(2009). "Caña de azúcar y aguardiente en el Estado Soberano de Bolívar, 1857-1886". En: Cuadernos de desarrollo rural Vol. 6, $N^{\circ}$ 63. Bogotá: Universidad Javeriana, pp. 35-58.

Gilmore, Robert Luís. (1995). El federalismo en Colombia, 1810-1858. 2 Tomos. Santa fe de Bogotá: Coed. Sociedad santanderista de Colombia y Universidad Externado de Colombia.

González, Fernán. (1997). "Problemas políticos y regionales durante los gobiernos del Olimpo Radical". En: Para leer la política. Ensayos de historia política colombiana, Tomo.2. Bogotá: Cinep, pp. 189-208.

González, Jorge Enrique. (2005). Legitimidad y cultura en los Estados Unidos de Colombia. La reforma de la instrucción pública en el Estado Soberano de Cundinamarca, 1863-1880. Bogotá: Universidad Nacional de Colombia.

Helg, Aline. (2002). "El General Padilla en su laberinto: Cartagena en el decenio de 1820". En: Haroldo Calvo y Adolfo Meisel, (Comp.), Cartagena de Indias en el siglo XIX. Cartagena: Universidad Jorge Tadeo Lozano/Banco de la República.

Hong Hiu, Alberto. (1999). "Las finanzas públicas en el Estado Soberano de Bolívar, 1857-1886". En: Historia y Pensamiento $N^{\circ} 3$. Barranquilla: Universidad del Atlántico.

Jacobsen, Nils. (2007). "Liberalismo tropical": cómo explicar el auge de una doctrina económica europea en América Latina, 1780-1885". En: Historia Crítica $N^{\circ} 34$. Universidad de Los Andes: Bogotá, pp.119-148.

Jaramillo Uribe, Jaime. (2001). "Nación y Región en los orígenes del Estado nacional en Colombia". En: Ensayos de Historia social. Obras completas de Jaime Jaramillo Uribe. Bogotá: Coed: Ceso- Uniandes/Banco de la República y otros, pp. 262-279.

Laso, Marixa. (2006). "El día de la Independencia: una revisión necesaria. Acción política afrocolombiana y narrativas patrióticas criollas, Cartagena, 1809-1815. En: Revista de estudios sociales $N^{\circ} 32$. Bogotá: Universidad de los Andes. 
- (2007). "Un mito republicano de armonía racial: raza y patriotismo en Colombia, 1810-1812". En: Memorias del Simposio: "Cartagena de Indias durante la Independencia". Cartagena: Banco de la República/Observatorio del Caribe colombiano.

Laurent, Muriel. (2008). Contrabando en Colombia en el siglo XIX. Prácticas y discursos de resistencia y reproducción. Bogotá: Universidad de los Andes, 620 págs.

. (2009), "...Y todos ellos roban sus ciudadanos". Acerca del delito de contrabando en el siglo XIX. En: Historia Crítica $N^{\circ} 35$, Edición especial. Bogotá: Universidad de los Andes, pp. 102-125.

Lemaitre, Eduardo. (1983). Historia General de Cartagena, Tomo IV. La República. Bogotá: Banco de la República.

Meisel, Adolfo. (1987). “¿Por qué se disipó el dinamismo industrial de Barranquilla?”. En: Lecturas de economía № 23. Medellín: Universidad de Antioquia.

Mendoza Candelo, Alberto. (1996). Provincia de Cartagena, Estado Soberano de Bolívar: Poblamiento y división política. Primera Edición. Bogotá: Ed. Gráficas Ltda., 477 págs.

Múnera, Alfonso. (1998). El fracaso de la Nación. Región, clase y raza en el Caribe colombiano, 1723-1810. Bogotá: Coed. Banco de la República/ El Áncora Editores.

Nichols, Teodoro. (1973). Tres puertos de Colombia. Estudio sobre el desarrollo de Cartagena. Santa Marta y Barranquilla. Bogotá: Banco popular.

Ortiz Mesa, Luís Javier. (1987). El Federalismo en Antioquia, 1850-1880. Aspectos políticos. Medellín: Universidad Nacional.

Palacio, Marco. (1986). "La fragmentación regional de las clases dominantes en Colombia: Una perspectiva histórica". En: Estado y clases sociales en Colombia. Bogotá: Ed. Procultura.

Palacios, Marco \& Safford, Frank. (2002). Colombia, País Fragmentado sociedad dividida. Su historia. Bogotá: Grupo Editorial Norma, 744 págs.

Palti, Elías José. (1994). "Orden político y ciudadanía. Problemas y debates en el liberalismo argentino en el siglo XIX". En: Estudios Interdisciplinarios de América Latina y el Caribe Vol. 5, $N^{\circ} 2$.

Posada Carbó, Eduardo. (1985). "La Liga Costeña de 1919, una expresión de poder regional”. En: Boletín Cultural y Bibliográfico $N^{\circ} 3$, Vol. XXII. Bogotá: Banco de la República, pp.22-28. 
------.-. (1998), El Caribe colombiano. Una historia regional, 18701950, Bogotá, Coed. Banco de la República/ El Áncora Editores.

(2002). "Núñez y Cartagena en la política nacional, 18861894". En: Haroldo calvo y Adolfo Meisel (Comp.) Cartagena de Indias en el siglo $X I X$. Bogotá: Banco de la República.

Ramírez Bahamón, Jairo. "vicisitudes de la utopía escolar del radicalismo en el Tolima, 1863-1886”. En: WWW. Oto. To. IT. Com.

Ramírez Bustos, Pedro. (2002), Cultura política y cotidianidad electoral en el Estado de Santander, 1857- 1886, Bogotá, Ministerio de Cultura.

Rhenals, Ana Milena \& Flórez, Francisco. (2009). "Distintos sujetos bajo un mismo predicado: reflexión historiográfica sobre la historia empresarial en el Caribe colombiano". En: El taller de la Historia N 1, pp. 139-160.

Restrepo, Jorge \& Rodríguez, Manuel. (1986). "La actividad comercial y el grupo de comerciantes de Cartagena a finales del siglo XIX". En: Estudios sociales № 1. Medellín: Faes.

Riguzzi, Paolo. (2000). "Libre cambio y libertad económica en la experiencia latinoamericana, 1850-1896". En: Marcelo Carmagnani. Constitucionalismo y orden liberal en América, 1850-1920. Torino: Nova americana.

Ripoll, María Teresa. (2007). Empresarios centenaristas en Cartagena. Cuatro estudios de caso. Bogotá: Universidad de los Andes.

Revolución política sin renovación social. Bogotá: Universidad de los Andes.

Román, Raúl. (2002). "Memoria y contramemoria. El uso público de la memoria histórica en Cartagena". En: Desorden en la plaza. Modernización y memoria urbana. Cartagena: Instituto de patrimonio y cultura de Cartagena.

Saether, Steinar. (2005). Identidades e independencia en Santa Marta y Riohacha, 1750-1850. Bogotá: Ed. Icanh.

Sierra Mejía, Rubén. (2006). El radicalismo colombiano del siglo XIX. Bogotá: Universidad Nacional, 398 págs.

Solano, Sergio. (1994). "Acumulación de capital e industrias. Limitaciones en el desarrollo fabril de Barranquilla, 1900-1934". En: Historia y Cultura № 2. Cartagena: Universidad de Cartagena. 
-. (2003). Puerto, Sociedad y conflicto en el Caribe colombiano, 18501930. Cartagena: Coed. Observatorio del Caribe/ Ministerio de Cultura y Universidad de Cartagena.

Solano, Sergio, Flórez, Roicer \& Malkún, William. (2008). "Ordenamiento territorial y conflictos jurisdiccionales en el Bolívar Grande, 1800-1886". En: Historia Caribe $N^{\circ}$ 13, Barranquilla: Universidad del Atlántico, pp.65-120.

Striffler, Luis. (1958). El rio San Jorge, Edición financiada por los hermanos Dr. Carmelo Ojeda Zapa y Arístides Ojeda Zapa.

Támara, Edgardo. (1997). Historia de Sincelejo. De los Zenues al Packing House. Bogotá: Findeter, 253 págs.

Troncoso, Luís. (2001), "Crisis y renovación del conservatismo cartagenero, 18951909", en: El Taller de la Historia N 1. Cartagena: Universidad de Cartagena.

Uribe de Hincapié, María Teresa \& Álvarez, Jesús María. (1987). Poderes y Regiones en la construcción de la Nación Colombiana, 1810-1850. Medellín: Universidad de Antioquia.

Valencia Llano, Alonso. (1998). Estado Soberano del Cauca. Federalismo y Regeneración. Bogotá: Banco de la República, 297 págs.

Verbel, Greis. (2009), "Elites y redes de poder en torno al proyecto regenerador. Cartagena, 1874-1892". En: El Taller del historiador N 1. Cartagena: Universidad de Cartagena.

Viloria, Joaquín. (2001). "Ganaderos y comerciantes en Sincelejo, 1880-1920". En: Cuadernos de historia empresarial y económica $N^{\circ}$ 8. Cartagena: Banco de la República.

(2002). Empresas y empresarios de Santa Marta durante el siglo XIX: El caso de la familia De Mier. Bogotá: Universidad de los Andes.

Villegas, Luís Javier. (1991). Aspectos de la educación en Antioquia durante el gobierno de Pedro Justo Berrío 1864-1873. Medellín: Secretaría de educación y cultura de Antioquia.

Zambrano, Milton. (1998). El desarrollo del empresariado en Barranquilla. Barranquilla: Uniatlántico.

Recibido: Octubre 5 de 2011

Aprobado: Noviembre 29 de 2011 